\title{
Hydrophobin can prevent secondary protein adsorption on hydrophobic substrates without exchange
}

\author{
Bernhard von Vacano $\cdot$ Rui Xu $\cdot$ Sabine Hirth • \\ Ines Herzenstiel • Markus Rückel • \\ Thomas Subkowski • Ulf Baus
}

Received: 17 January 2011 /Revised: 25 February 2011 / Accepted: 11 March 2011 /Published online: 5 April 2011

(C) The Author(s) 2011. This article is published with open access at Springerlink.com

\begin{abstract}
By combining several surface analytical tools, we show that an adsorbed layer of the protein $\mathrm{H}^{*}$ Protein $\mathrm{B}$ prevents the adsorption of secondary proteins bovine serum albumin, casein, or collagen at low-salinity conditions and at $\mathrm{pH} 8 . \mathrm{H}^{*}$ Protein $\mathrm{B}$ is an industrially producible fusion protein of the hydrophobin family, known for its high interfacial activity. While applications of hydrophobin have been reported to facilitate adhesion of proteins under different $\mathrm{pH}$ conditions, careful analysis by quartz-crystal microbalance and ellipsometry prove that no additional adsorption can be found on top of the $\mathrm{H}^{*}$ Protein $\mathrm{B}$ layer in this study. Surface analysis by X-ray photoelectron spectroscopy and secondary ion mass spectrometry proves that the hydrophobin layer stays intact even after hours of exposure to solutions of the secondary proteins and that no exchange of proteins can be detected.
\end{abstract}

Keywords Hydrophobin · Protein adsorption · Secondary ion mass spectrometry . Quartz-crystal microbalance . $\mathrm{X}$-ray photoelectron spectroscopy

B. von Vacano $(\bowtie) \cdot$ R. Xu $\cdot$ S. Hirth $\cdot$ I. Herzenstiel $\cdot$ M. Rückel Polymer Physics, BASF SE,

Carl-Bosch-Str. 38,

67056 Ludwigshafen, Germany

e-mail: bernhard.von-vacano@basf.com

T. Subkowski

Biotechnology Research, BASF SE,

Carl-Bosch-Str. 38,

67056 Ludwigshafen, Germany

U. Baus

Performance Chemicals Division, BASF SE,

Carl-Bosch-Str. 38,

67056 Ludwigshafen, Germany

\section{Introduction}

Adsorption of proteins plays a vital role in a number of processes on technically or medically relevant materials, for example, in pellicle formation on teeth or dental materials [1] or during the primary stages of urinary tract infection. The latter usually involves microbial adhesion on catheter surfaces covered with a conditioning film $[2,3]$. Sometimes, a targeted surface modification is desired to control the biocompatibility of implanted materials and sensors [4, 5].

Especially interesting candidates for surface modification can be found within the group of hydrophobins. These are relatively small amphiphilic proteins (about 100 amino acids) naturally occurring in filamentous fungi. As a major biological function, they hydrophobize fungal spores and allow them to be easily dispersed and liberated [6-8]. Thus, remarkable surface activity is a characteristic for these proteins [9]. It could be shown that hydrophobins easily cover surfaces even under in vitro or technical conditions, assembling both on hydrophobic Teflon ${ }^{\circledR}$ or hydrophilic glass. Thereby the respective surface polarity is reversed $[10,11]$. The high interfacial activity also manifests itself at oil-water or air-water interfaces, beneficially exploited in a number of technical applications such as boosting emulsification by the addition of parts per million amounts of protein to solutions of technical surfactants [12], a significantly improved stability of foams or thin film depositioning [13]. The main hurdle for any technical application, however, is the availability of protein in industrial quantities. From natural sources, hydrophobins are available only in milligram amounts, while BASF succeeded in a recombinant production process, up-scaled to pilot plant production in kilogram scale. The optimization by modulation of gene expression as well as the generation of various fusion proteins finally lead to two artificial hydrophobins variants called $\mathrm{H}^{*}$ Protein A 
and $\mathrm{H}^{*}$ Protein B [12]. Both proteins belong to "class I" hydrophobins distinguished from "class II" types by their spacing between the cystein residues [14]. Class I hydrophobins exhibit unusual stability versus solvents and detergents making them ideal for deliberate surface modifications [9]. Apart from technical uses for emulsification, improved wetting or adhesion of coatings, applications are being discussed to use such hydrophobin layers for controlling interactions with other proteins.

In this context, it was shown that certain hydrophobins can help in recruiting enzymes from solution to a surface and thus accelerate degradation of the substrate [15]. Additionally, hydrophobin layers have been reported for surface immobilization of enzymes to create catalytic surfaces for sensing applications [16]. These effects make use of hydrophobin to facilitate adhesion of a secondary protein on a surface, and the underlying mechanisms based on oppositely charged moieties have been studied recently in detail [17]. However, the ability of hydrophobin to convert a hydrophobic surface into a clearly hydrophilic one should also allow prevention of secondary protein adsorption under suitable charge conditions. Furthermore, its stability in adsorbed state and high surface affinity should make hydrophobin films stable against exchange being exposed to secondary proteins. To test these hypotheses and carefully analyze the aspect of protein exchange, we study adsorption on a model hydrophobic surface (octadecane thiol SAM on gold). The required surface analytical methodology will be presented here, combining techniques which both allow quantification of surface coverage as well as qualitative (bio-)chemical analysis: quartz-crystal microbalance with dissipation (QCM-D), spectroscopic ellipsometry, X-ray photoelectron spectroscopy (XPS), and time-of-flight secondary ion mass spectrometry (ToF-SIMS).

\section{Experimental}

\section{Sample preparation}

The substrates used in this study are commercially available sensor crystals for the QCM-D method (QSX 301, Q-Sense $\mathrm{AB}$, Sweden), having a diameter of about $14 \mathrm{~mm}$ and coated with 100-nm gold. These substrates were used for in situ QCM-D measurements as well as ex situ measurements on the same substrate. Alternatively, for reproduction and ex situ measurements, one-side polished p-type singlecrystal Si (100) wafers with a natural top oxide layer have been used after plasma cleaning for $10 \mathrm{~min}$ and applying a 40 -nm gold top layer by physical vapor depositioning. For handling convenience, the wafers were broken into rectangular pieces of roughly $1 \mathrm{~cm} \times 2 \mathrm{~cm}$ dimension. To create our hydrophobic model surface, the gold-coated crystals or wafers were immersed in a 1-mM solution of octadecanethiol in ethanol at room temperature over night. In the case of QCM-D sensors, the process was also followed in situ in the instrument for several samples, proving formation of a thiol layer of $160 \mathrm{ng} / \mathrm{cm}^{2}$ area mass within the first hour, not changing any more over the complete immersion time. After treatment with thiol solution, all substrates were thoroughly rinsed first with ethanol and then with distilled water prior to use. Ex situ spectroscopic ellipsometry confirmed SAM formation and detected a layer thickness of $1.5 \pm 0.2 \mathrm{~nm}$.

The hydrophobin solution at an active concentration of 0.02 wt. $\%$ was prepared by dissolving $15.4 \mathrm{mg} \mathrm{H}$ Protein B (BASF SE, class I, 65\% purity, and molecular weight $18.8 \mathrm{kDa}$ ) in $50 \mathrm{~g}$ of a $12.5 \mathrm{mM} \mathrm{NaCl}$ solution in millipore water. The $\mathrm{pH}$ value of the solution was kept at 8.0 by $\mathrm{NaOH}$ addition. To ensure complete dissolution, $48 \mathrm{~h}$ stirring time were allowed. It was filtered with a $5-\mu \mathrm{m}$ syringe filter to obtain a clear solution. The first milliliters of filtrate were always discarded to avoid protein depletion due to initial surface coverage of the filter.

The other protein solutions were prepared at $0.1 \mathrm{mg} / \mathrm{mL}$ concentration with bovine serum albumin (BSA) $(>98 \%$ purity, $\sim 66 \mathrm{kDa}$; Sigma-Aldrich), casein (alkali-soluble, $>95 \%$ purity, $\sim 25 \mathrm{kDa}$; Merck), and collagen (type III, $\sim 75 \%$ purity, $\sim 140 \mathrm{kDa}$; Sigma-Aldrich); $5 \mathrm{mg}$ of protein was added each into $50-\mathrm{mL}$ aqueous $12.5 \mathrm{mM} \mathrm{NaCl}$ solution and stirred for $8 \mathrm{~h}$. The $\mathrm{pH}$ was adjusted to 8.0.

If protein adsorption was not carried out in situ in the QCM-D on the respective sensors, hydrophobin was adsorbed on silicon wafers with gold-alkylthiol SAMs as follows: the wafers were immersed horizontally in the $\mathrm{H}^{*}$ Protein solution for $15 \mathrm{~h}$, rinsed with distilled water, immersed in fresh distilled water for $3 \mathrm{~h}$, rinsed again and subsequently blown dry with nitrogen. To study secondary adsorption, each piece of wafer was immersed horizontally in the respective protein solution of BSA, casein, or collagen for $15 \mathrm{~h}$. The wafers were again rinsed with distilled water, immersed for $3 \mathrm{~h}$, rinsed again, and subsequently blown dry with nitrogen. This procedure allowed studying the samples step by step with the various surface analytical techniques employed in this work.

\section{Ellipsometry measurements}

Spectroscopic ellipsometry was measured in the wavelength range between $380-900 \mathrm{~nm}$ at a fixed angle of incidence of $70^{\circ}$ (J. A. Woollam alphaSE). For all substrates, a base characterization was performed on the gold-coated substrates, both QCM-D sensors and silicon wafers. Average optical constants were determined for both types of gold surfaces (Bspline material fit implemented in the measurement software 
CompleteEASE). On this basis, the formation of the octadecanethiol SAM could be monitored for each prepared substrate. Assuming a wavelength-dependent refractive index described by a truncated Cauchy parametrization to be $n(\lambda)=$ $A+B / \lambda$ where $A=1.45$ and $B=0.01$, protein adsorbates were characterized similarly, with the same fixed parameters for the refractive index, determining a total optical thickness of all "organics" on the gold surface. The known, previously measured thickness of the thiol SAM was subtracted from this total optical thickness to give a value for the adsorbed protein. For ellipsometry, three positions were measured on each sample. Reported thicknesses are the average of these measurements, and the indicated error is the respective standard deviation.

\section{QCM-D measurements}

Quartz sensors used were either used as described above after ex situ modification with the octadecanethiol. Alternatively, for in situ studies starting from the thiol SAM formation, goldcovered quartzes (QSX 301, Q-Sense AB, Sweden) were cleaned before the experiment in subsequent ethanol and water in an ultrasonic device for $10 \mathrm{~min}$ and then using another $10 \mathrm{~min}$ of plasma cleaning $\left(10 \mathrm{~min}, 50 \mathrm{~W}, \mathrm{O}_{2}\right.$ at 0.2 mbar). After mounting in the QCM-D system (QCM-D D4, Q-Sense AB, Sweden) and acquisition of the resonance frequencies, the sensors were always equilibrated for typically $30 \mathrm{~min}$ to ensure stable frequency readings in the respective buffer (ethanol for thiol SAM formation, aqueous $12.5 \mathrm{mM} \mathrm{NaCl}$ for protein adsorption experiments). All experiments were carried out in a flow-cell set-up with a constant flow rate of $250 \mu \mathrm{L} / \mathrm{min}$. For exchanging solutions at the QCM-D inlet, the flow was interrupted briefly. The mass coverage of adsorbed proteins was evaluated using the Sauerbrey equation [18] $\Delta m=-17.54 \mathrm{ng} /\left(\mathrm{Hz} \mathrm{cm}^{2}\right) \cdot \Delta f$, because adsorbates proved to be rigid, as could be seen from small dissipation changes (below $1 \mathrm{ppm}$ unless stated otherwise). Frequency differences $\Delta f$ (as well as dissipation) are measured at the seventh harmonic $f_{7}$ of the fundamental quartz oscillation frequency and reported as normalized value $\Delta f=\Delta f_{7} / 7$. By injection of $5 \% \mathrm{NaCl}$ solution, the dead time of the QCM-D flow cell was determined to be $40 \mathrm{~s}$. The expected "rectangular" response in frequency and dissipation due to the change in bulk fluid density and viscosity occurred within $10 \mathrm{~s}$. This is in agreement with a flow-cell volume of $\sim 40 \mu \mathrm{L}$ and a laminar exchange, limiting the fastest measureable kinetics.

\section{ToF-SIMS measurements and data analysis}

Static ToF-SIMS spectra were recorded using a ToF-SIMS V spectrometer (IonTOF GmbH, Germany). A pulsed mass- filtered primary ion beam of $25 \mathrm{keV}$ singly charged triple bismuth clusters $\left(\mathrm{Bi}_{3}{ }^{+}\right)$was used. This primary ion beam, resulting in a spot size of typically $5 \mu \mathrm{m}$ on the sample surface, was raster scanned over an area of $400 \mu \mathrm{m} \times$ $400 \mu \mathrm{m}$ to record spectra of positive and negative secondary ions. The primary ion dose density was always kept well below $10^{12}$ ions $/ \mathrm{cm}^{2}$ and thus in the static SIMS regime. To prevent charging of the sample surface, a lowelectron energy flood gun was used. SIMS spectra were recorded on three different positions with several millimeter spacing for each substrate to assess lateral homogeneity and make the measurement robust against possible local surface contaminations.

Principle component analysis (PCA) of the positive ToFSIMS spectra was performed following closely the procedure described in literature by Suzuki et al. From the carefully calibrated ToF-SIMS spectra, peak lists were generated containing relevant protein secondary ions on the basis of ref. [19], summarized in Table 1. The principal component analysis itself was performed using BASFsoftware developed in LabVIEW (version 7.1, National Instruments). Based on built-in LabVIEW matrix algebra, this software implements PCA following ref. [20]. Briefly, all $m=37$ peak areas from the list (Table 1) are normalized with respect to the sum of the total areas and mean-centered by subtracting the average area each. From such pretreated data of $n$ samples, a data matrix $X$ of dimension $(n \times m)$ is constructed. From $X$, the covariance matrix $Z_{\mathrm{cov}}=X^{\prime} X$ is computed and diagonalized to yield its eigenvectors and eigenvalues. The PCA factors consist of the eigenvectors $q_{i}$, sorted in descending order of their eigenvalues. Any measured SIMS data can now be expressed by the linear combination of $q_{i}$. The respective coefficients are called the PCA scores, while the eigenvectors $q_{i}$ constitute the PCA loadings of the respective principal component $i$. For a reduction of dimensionality of the data, higher PCA factors $i>i_{\max }$ can be discarded. As a criterion of $i_{\max }$, the scree test [20] is applied in our case showing that $99 \%$ of all variance between the samples is captured by only three PCA factors $\left(i_{\max }=3\right)$. Inclusion of negative spectra in the analysis neither changed nor improved the results and thus was not pursued further.

\section{XPS measurements}

XPS analyses were performed with a Phi (Physical Electronics) 5600LS XPS/ESCA-spectrometer using monochromatic $\mathrm{K} \alpha$-aluminum $\mathrm{X}$-rays $(1,486.6 \mathrm{eV}, 300 \mathrm{~W})$ with a spot size of $0.8 \mathrm{~mm} \times 0.8 \mathrm{~mm}$.

A charge neutralization system with a low energy electron flood neutralizer and a low energy ion beam neutralizer was used to compensate for sample charging. 
Table 1 Peak list used for ToF-SIMS principal component analysis together with the loadings of the three dominating principal components

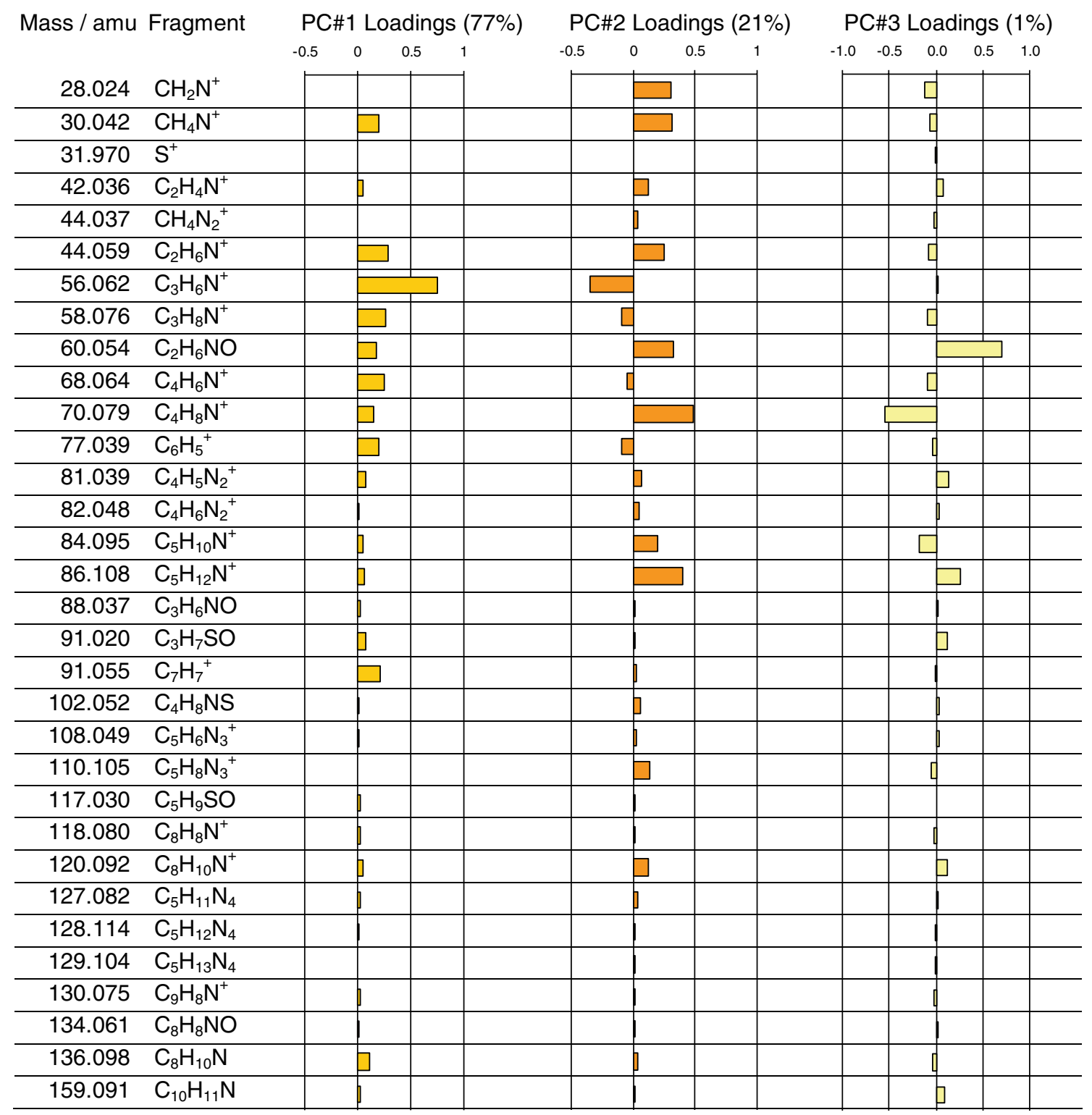

Survey spectra were acquired covering a binding energy range of 1,350 to $0 \mathrm{eV}$ with a step size of $0.5 \mathrm{eV}$, pass energy of $117.4 \mathrm{eV}$ and a dwell time of $1 \mathrm{~s} /$ point.

High resolution spectra of the elements of interest, namely oxygen, nitrogen, sulfur, carbon, and gold were acquired in a range of $\pm 10 \mathrm{eV}$ from the peak maximum with pass energy of $23.5 \mathrm{eV}$, step size of $0.1 \mathrm{eV}$, dwell time of 1.1-2.2 s/point. Data analysis was conducted using the software CasaXPS [21] applying a standard Shirley background [22] subtraction and sensitivity factors for the 5600 LS provided by the XPS manufacturer. All spectra were corrected using the tabulated binding energy of the gold $\mathrm{Au} 4 \mathrm{f}$ signal at a position of $84.0 \mathrm{eV}$ [23]. The necessary correction of the binding energy scale was in the range of $+0.9 \mathrm{eV}$ for all measurements.

\section{Results and discussion}

As basis for our work, the adsorption of BASF's Hydrophobin $\mathrm{H}^{*}$ Protein $\mathrm{B}$ on a hydrophobic model substrate was investigated. In reality, a typical hydrophobic substrate in a technical application might be the surface of a thermoplastic polymer or polymeric coating. Such technical surfaces, however, are not too well defined mostly due to presence of additives from production. Octadecanethiol SAMs on gold, on the other hand, represent a well-defined, reproducible surface compatible with a wide range of surface analytical techniques. Thus, such model substrates have been used in this study. Similarly, we chose to keep the aqueous medium for our adsorption studies as simple as possible. For reproducibility, a $\mathrm{pH}$ of 8 was adjusted with $\mathrm{NaOH}$ and a 
low ionic strength fixed by $12.5 \mathrm{mM}$ sodium chloride in the buffer.

\section{Single protein adsorption}

$\mathrm{H}^{*}$ Protein B adsorption could be followed in situ in real time with QCM-D (Fig. 1). QCM-D determines the mass of surface-bound material including possible hydration [24, $25]$ and the viscoelastic properties[26] of the bound layer. A decrease in frequency corresponds to an increase in bound mass. Within less than $10 \mathrm{~min}$ after initial injection of the $\mathrm{H}^{*}$ Protein B solution (point B in Fig. 1), the measured QCM oscillation frequency rapidly drops reaching a plateau at $-50 \mathrm{~Hz}$. Upon switching back to buffer (point $\mathrm{C}$ in Fig. 1), immediate frequency recovery of $17 \mathrm{~Hz}$ is found. During protein solution exposure, the dissipation also increases almost instantly. This indicates contributions of changes in bulk liquid properties (viscosity and density) between protein solution and pure buffer. Finally, a stable frequency reading in buffer is reached at $-33 \mathrm{~Hz}$. From this value, a mass coverage of $\mathrm{H}^{*}$ Protein $\mathrm{B}$ of $580 \mathrm{ng} / \mathrm{cm}^{2}$ irreversibly adsorbed can be calculated. This experiment is well reproducible: it has been performed four times, showing deviations in the determined $\mathrm{H}^{*}$ Protein $\mathrm{B}$ adsorption within only $3 \%$. Even upon rinsing of one coated sensor for several days ( $\sim 62 \mathrm{~h}$ ), a maximum desorption of $5 \% \mathrm{H} *$ Protein could be found. Assuming a density of $1 \mathrm{~g} / \mathrm{cm}^{3}$, a gravimetric $\mathrm{H}^{*}$ Protein layer thickness of $5.8 \mathrm{~nm}$ results from the area mass coverage. For further analysis, the three other experimental QCM-D runs were interrupted at the end of the measurement in Fig. 1 and the quartz sensors dismounted. Ex situ ellipsometry thickness measurements on the sensors after drying with nitrogen showed an optical layer thickness of $3.3 \pm 0.3 \mathrm{~nm}$ for dry adsorbed $\mathrm{H}^{*}$ protein. Substrates incubated ex situ in $\mathrm{H}^{*}$ Protein $\mathrm{B}$ solution over night resulted in exactly the same ellipsometric thickness. The apparent discrepancy between the gravimetric thickness of roughly $6 \mathrm{~nm}$ by QCM and the clearly lower optical thickness of only $60 \%$ results from the different measurement principles: While QCM-D also measures surface-bound water, ellipsometry only detects adsorbed protein in its dry state $[25,27]$.

For comparison, BSA, casein, and collagen were also adsorbed on the thiol SAM substrates, partly also again in situ in the QCM (Fig. 2). It can be seen that all three proteins readily adsorb on the hydrophobic surface. For BSA, no desorption is seen upon rinsing with buffer. While casein also shows negligible desorption of less than $10 \%$ measured by QCM-D frequency, collagen behaves differently: first of all, a sudden drop of about $10 \mathrm{~Hz}$ in frequency is followed by a further slow decrease, which does not reach equilibrium within the allowed adsorption time of $90 \mathrm{~min}$. Additionally, this adsorption curve is the only case within this study where a significant increase in dissipation of roughly $10 \mathrm{ppm}$ was measured by QCM-D. However, upon switching back to buffer (Fig. 2, point C) the mass sensed by frequency rapidly decreases leveling out at $-20 \mathrm{~Hz}$. At the same time, dissipation decreases to a value below $1 \mathrm{ppm}$, indicating again a compact, rigid protein layer after rinsing. This means that the adsorbed mass after rinsing can be evaluated using the Sauerbrey equation, while the slow built-up dynamics and marked layer softness during adsorption can most probably be attributed to the known supermolecular association of collagen upon adsorption [28, 29]. Measurements of the same

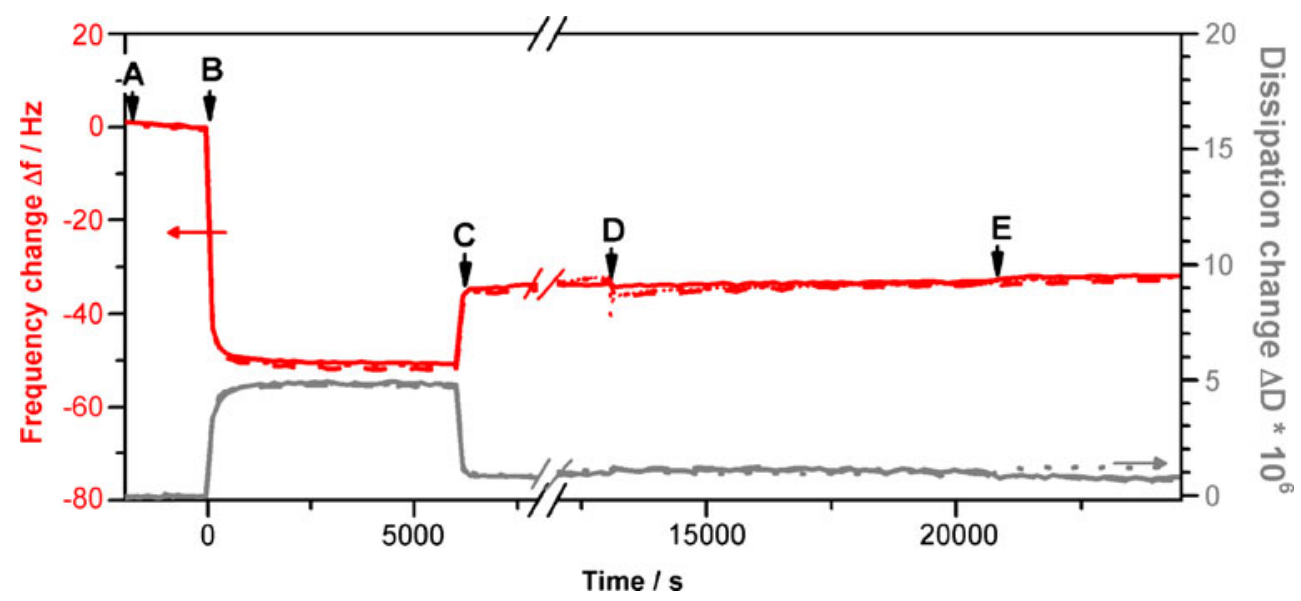

Fig. 1 QCM-D frequency (red) and dissipation (gray) traces showing sequential adsorption of $\mathrm{H}^{*}$ Protein $\mathrm{B}$ and secondary proteins (solid line, collagen; dashed line, BSA; dotted line, casein) on octadecanethiol. At the beginning, the sensor was rinsed in buffer (A) while at time zero (B), $\mathrm{H}^{*}$ Protein solution was injected leading to rapid and clear adsorption. At point $(\mathbf{C})$, the system was switched again to pure buffer. At (D), the respective secondary protein solution was injected, showing no additional adsorption in all three cases. Finally, the flow cell was again rinsed with buffer $(\mathbf{E})$. The break in the abscissa has been introduced for better visibility of the data. It indicates over an hour of rinse in buffer, where no significant changes in frequency or dissipation occurred 


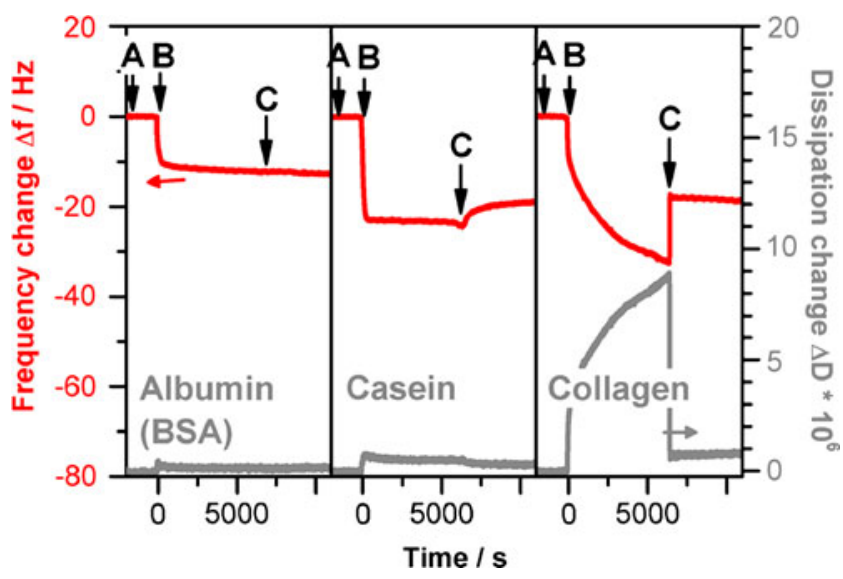

Fig. 2 QCM-D frequency trace showing adsorption of albumin (BSA), casein, and collagen on neat octadecanethiol SAM on gold. After establishing a baseline in buffer (A), at time zero (B) the respective protein solutions were injected and adsorption is found in all cases. At point (C), the system was switched back to buffer, where some slow desorption occurs for casein and immediate partial desorption of collagen

protein adsorption sequence by ellipsometry confirm these findings. Again, as in the case of $\mathrm{H}^{*}$ Protein adsorption, the optically detected thickness is smaller than the gravimetric thickness by QCM. All measured layer thicknesses after rinsing are summarized in Fig. 3. It can be seen that the

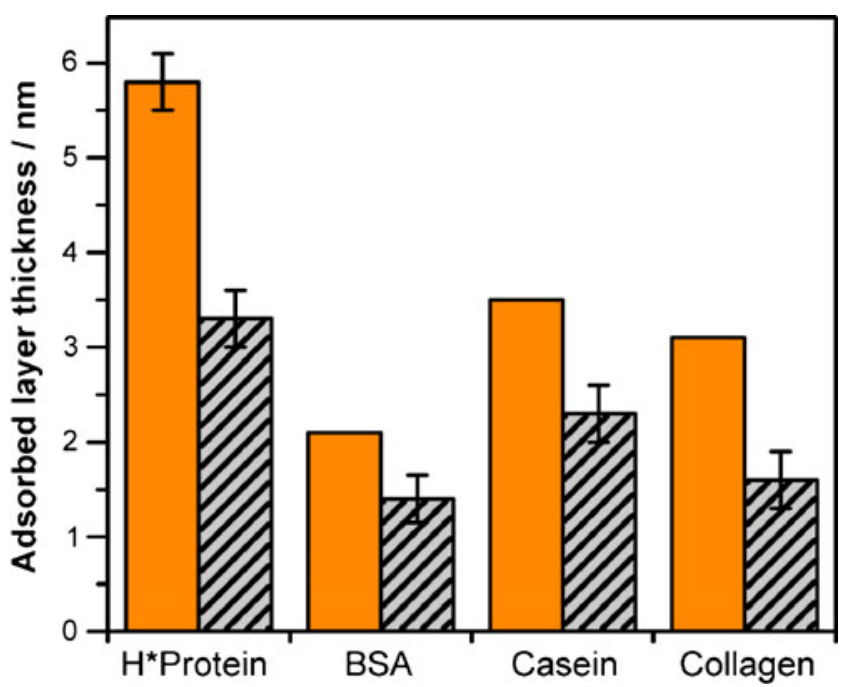

Fig. 3 Resulting thicknesses of adsorbed proteins on octadecanethiol SAM. Gravimetric thickness by QCM-D (orange solid bars) always shows a higher thickness due to surface-bound water as compared to dry ellipsometric thickness (gray hatched bars). The error bar for the QCM-D thickness of adsorbed $\mathrm{H}^{*}$ Protein indicates the standard deviation of four independent experiments. For the other proteins, a single QCM-D experiment was conducted each and thus no error bars are reported. For ellipsometric thickness, the error bars indicate the standard deviation of three measurements relative amounts adsorbed are the same independent of the measurement technique.

\section{Sequential adsorption}

The next step was to study the interaction of a first adsorbed layer of $\mathrm{H}^{*}$ Protein with the other "secondary" proteins. In the previous section, we have established independently by QCM-D and ellipsometry that all three other proteins (BSA, casein, and collagen) readily adsorb on the hydrophobic substrate under the given conditions. For in situ studies of secondary adsorption, $\mathrm{H}^{*}$ Protein-coated QCM-D sensors were used. As seen in the QCM-D traces (Fig. 1) after $\mathrm{H}^{*}$ protein adsorption, at $13,000 \mathrm{~s}$ (point $\mathrm{D}$ ), solutions of collagen (solid line), BSA (dashed line), and casein (dotted line) were injected respectively and allowed to adsorb for $2 \mathrm{~h}$ before rinsing again with buffer (point E). The measured curves almost completely overlap: no secondary adsorption on top of the $\mathrm{H}^{*}$ Protein occurs, as no significant further frequency decrease is found. This was also confirmed in all cases by ex situ experiments evaluated by ellipsometry after a short or $10 \mathrm{~h}$ rinse with buffer. The summarized results (Fig. 4) show that conclusively with both methods no adsorption can be found. On the other hand, in some cases even a slight desorption of total adsorbed mass is seen, which, however, is partly within the error from ellipsometry

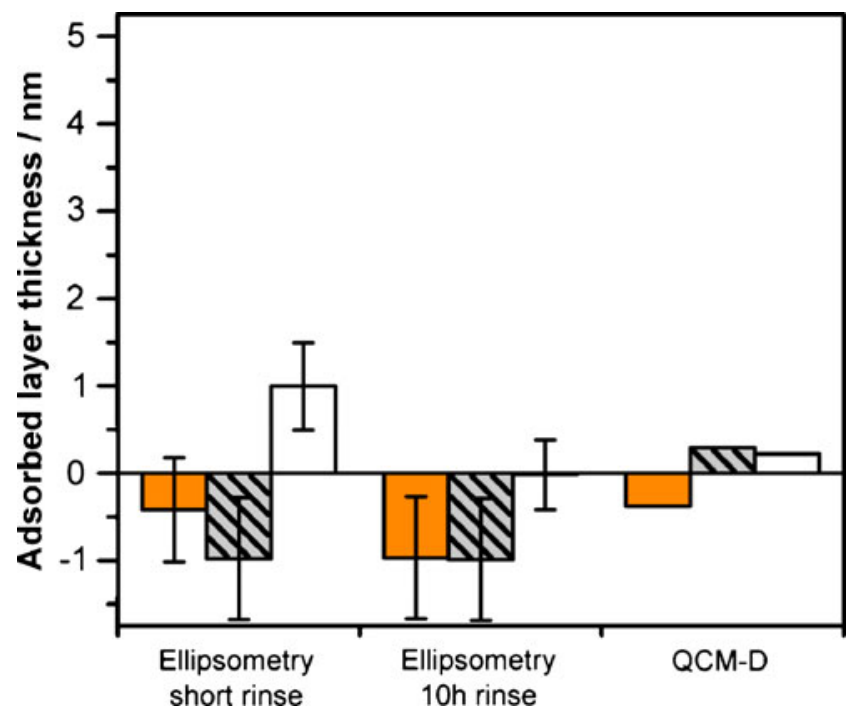

Fig. 4 Resulting thicknesses of proteins on pre-adsorbed $\mathrm{H}^{*}$ Protein layer. No significant thickness increase can be found for all BSA (orange solid bars), casein (gray hatched bars), and collagen (white open bars). The error bars indicated for ellipsometric thickness are the standard deviation of three measurements 
$( \pm 0.3 \mathrm{~nm}$ alone from uncertainty of initial thiol SAM thickness measurement) and/or in line with the maximum $\mathrm{H}^{*}$ Protein desorption of $5 \%$ total layer thickness found earlier. Note that the QCM-D layer thicknesses shown in Fig. 4 have been calculated from the frequency traces in Fig. 1 after point $\mathrm{E}$ from the average frequency in a $300 \mathrm{~s}$ interval, relative to the $\mathrm{H}^{*}$ Protein thickness measured similarly before point $\mathrm{D}$.

These findings from two independent methods show that $\mathrm{H}^{*}$ Protein is capable of blocking the hydrophobic surface and preventing secondary adsorption under the given conditions of $\mathrm{pH} 8$ and $12.5 \mathrm{mM} \mathrm{NaCl}$ salinity. This might seem contradictory to descriptions of hydrophobins acting to effectively promote protein adhesion $[15,17]$. However, the detailed study of adhesion mechanisms on two different hydrophobins (HGFI and HFBII) by Wang et al. already points to this twofold behavior. In their study, secondary adsorption was studied as a function of $\mathrm{pH}$ and ionic strength. It was shown that adhesion only occurs in the case where an underlying hydrophobin layer and the secondary protein in the solution are oppositely charged, which is the case in a $\mathrm{pH}$ range between the isoelectric points of both molecules [17]. One of the proteins studied was BSA: adhesion only occurred between $\mathrm{pH} 4$ and 6.5. Thus, even though we have studied a different hydrophobin $\left(\mathrm{H}^{*}\right.$ Protein B), the BSA data are in full accordance with our findings. Class I hydrophobin was reported with an isoelectric point pI of 5.7 [17] while BSA has a pI of 4.5 [30]. At pH 8, both molecules are negatively charged. The prevention of casein adsorption on hydrophobin, studied in our contribution, can also plausibly be explained by the same mechanism: casein has a reported $\mathrm{pI}$ of $\sim 4.6$ [31]. Collagen on the other hand is reported with a $\mathrm{pI}=8.2$. Hence, at $\mathrm{pH} 8$ it should be almost neutral or slightly positively charged. However, collagen did not adhere at all to the $\mathrm{H}^{*}$ Protein layer under these conditions (Fig. 1). It might be that the difference in charge still is not high enough and the $\mathrm{pH}$ region for adsorption shifted towards higher $\mathrm{pH}$ values as seen before for some proteins [17]. Alternatively, an additional mechanism of repellency could be acting here with $\mathrm{H}^{*}$ Protein B. This question deserves further clarification in future investigations.

Independently, the fact of no additional layer thickness or adsorbed mass detected does not yet constitute sufficient proof for preventing secondary protein adsorption: for many systems, it is well known that adsorbed proteins are displaced by different species from solution [32] - possibly resulting in a constant adsorbed mass but a change of adsorbate composition over time. This question cannot be answered alone by techniques determining total protein coverage on a surface. On the contrary, a (bio)chemical analysis of the surface composition of the protein adsorbate is necessary. This is only possible by complementing
QCM-D and ellipsometry with dedicated surface analytic techniques in a multi-method approach.

\section{Surface analytics: XPS+SIMS}

ToF-SIMS is a powerful surface analysis technique that allows chemical characterization of the first atomic layers of any vacuum stable solid surface. The information depth is restricted to the first few nanometers. Being a fragmenting mass spectrometry technique, it provides a wealth of chemical information and allows identifying compounds with very high sensitivity. This makes ToF-SIMS ideally suited to characterize and study biomolecules, such as proteins, on surfaces. Quantification, however, is only possible by calibration with standards. XPS on the other hand allows direct absolute quantification, providing elemental and general chemical information on the basis of chemical shifts of the binding energy.

A first look on ToF-SIMS data of the bare octadecanethiol surface (Fig. 5a) and $\mathrm{H}^{*}$ Protein adsorption (Fig. 5b) reveals marked differences and again proves $\mathrm{H}^{*}$ Protein adsorption. The dominating secondary ions of the octadecanethiol layer on gold are typical alkyl fragments $\mathrm{C}_{\mathrm{n}} \mathrm{H}_{(2 \mathrm{n}+1)}{ }^{+}$and $\mathrm{Au}^{+}$ions. At higher masses, molecular ions of the thiol and additional thiol-gold clusters are detected. After $\mathrm{H}^{*}$ Protein adsorption, the typical alkyl fragment pattern is complemented by peaks very characteristic for proteins, especially at even masses, which have been marked in Fig. 5 b. $\mathrm{Au}^{+}$is still visible but at a drastically reduced intensity.

Upon quantitative evaluation of the integrated ToF-SIMS signals, the different samples of a pristine thiol substrate, single protein adsorptions and sequential protein adsorptions can be compared (Fig. 6). While the reference substrate does not show any secondary ion intensity for the selected characteristic protein fragment at $84 \mathrm{amu}$ (corresponding to $\mathrm{C}_{5} \mathrm{H}_{10} \mathrm{~N}^{+}$) and a maximum for $\mathrm{Au}^{+}$, this ratio reverses for the sample after $\mathrm{H}^{*}$ Protein adsorption. BSA also shows a marked reduction in $\mathrm{Au}^{+}$count rate although by far less than the Hydrophobin. Casein and even more collagen, on the other hand, show very high $\mathrm{Au}^{+}$ intensities. Knowing from QCM-D and ellipsometry that a significant protein layers are formed for these two species, this suggests that the layers cannot be completely closed. To corroborate that, atomic force microscopy was performed on the respective substrates which indeed showed dewetting of casein and collagen over time (data not shown here). Samples, where $\mathrm{H}^{*}$ Protein was adsorbed first and then subjected to the solution of the secondary proteins BSA, casein, and collagen, always gives the same high secondary ion intensities and $\mathrm{Au}^{+}$depression as pure $\mathrm{H}^{*}$ Protein layers. 
Fig. 5 ToF-SIMS spectra in the positive detection mode for masses 0-350 amu for a the reference octadecanethiol SAM and $\mathbf{b}$ adsorbed $\mathrm{H}^{*}$ Protein on top of that hydrophobic substrate a)
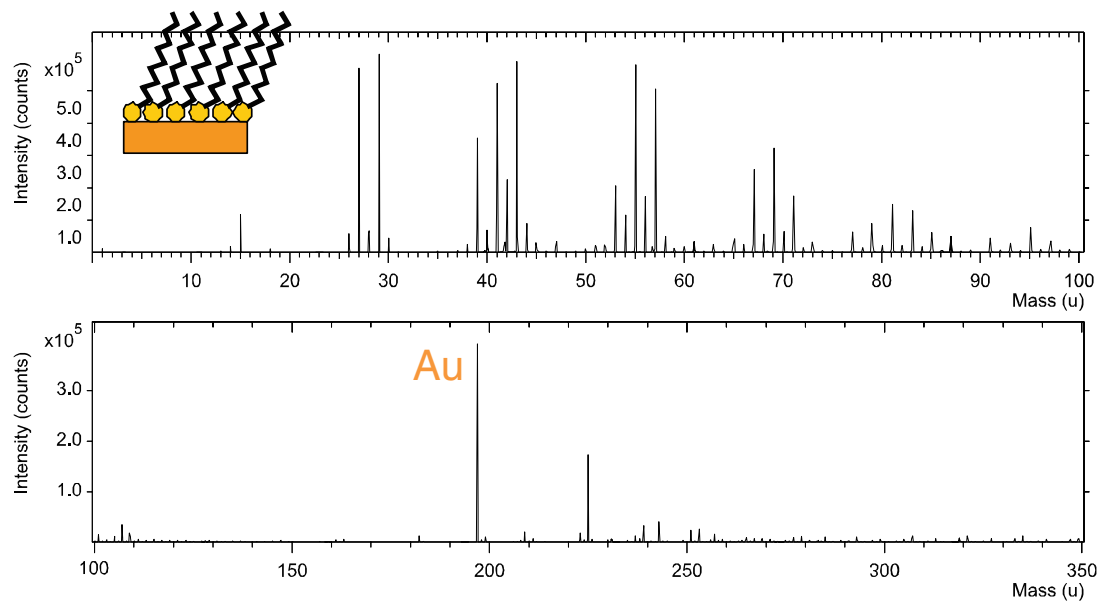

b)
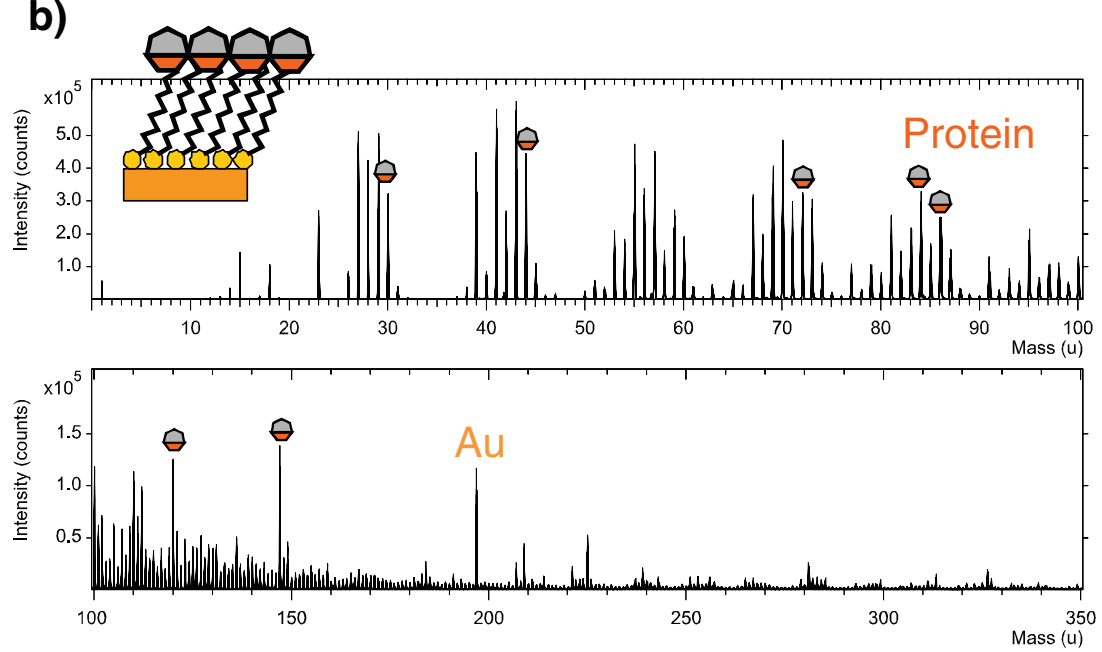

XPS was performed on the same samples. By the relative elemental concentration of gold detected on the surface in relation to the nitrogen content measured, the same trend in the amount of adsorbed protein was observed for the four different proteins. While the amount of gold was lowest for the $\mathrm{H}^{*}$ Protein layer (11.5 at.\%), it increased from BSA (19.5 at.\%) to casein (21.0 at.\%). Almost the same concentration as on the pure thiol layer was detected again for collagen (30.2 at.\% vs. 31.1 at. $\%$ for the thiol layer) indicating severe dewetting of the protein.

Also in XPS, samples with pre-adsorbed $\mathrm{H}^{*}$ Protein subjected to the solution of the secondary proteins BSA, casein, and collagen show no significant difference in the elemental composition as compared to a layer of pure $\mathrm{H}^{*}$ Protein on thiol, supporting the idea of a stable $\mathrm{H} *$ Protein layer.

For additional substantiation that no exchange is taking place between the adsorbed $\mathrm{H}^{*}$ Protein layer and the secondary proteins in the sequential adsorption experiments, the ToF-SIMS spectra were analyzed by PCA [20]. PCA facilitates clustering of different spectra according to the major differences between them and has proven a very powerful tool for the identification and quantification of mixed protein adsorbates [19, 20, 33-35]. The peak list used is shown in Table 1 including the loadings of the first three principal components, which together describe $99 \%$ of all variance in the dataset. In our analysis, we have used a peak list solely composed of protein-specific secondary ions, blanking out the most characteristic changes in the substrate signals from gold and thiol because we want to analyze changes in the protein layer composition. In Fig. 7, the scores of the first two principal components are plotted for all samples. It clearly shows that all $\mathrm{H}^{*}$ Protein samples perfectly cluster in the same area, while the other proteins lie in distinct completely separated regions. The data from the three different collagen spectra are spread out the most 


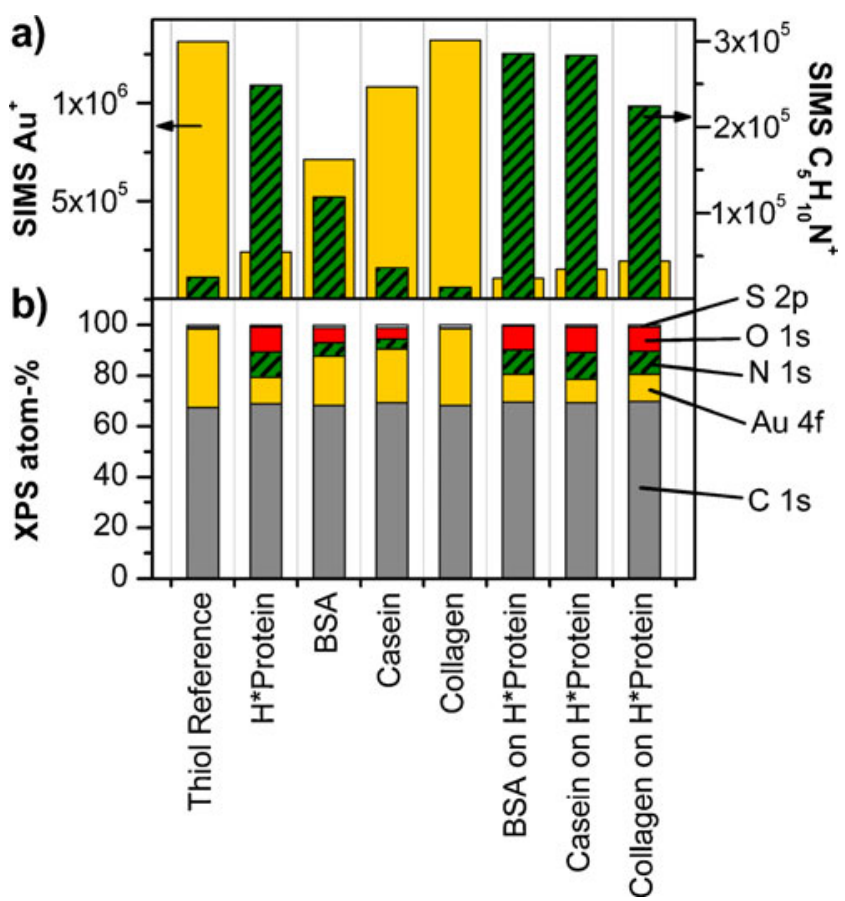

Fig. 6 a ToF-SIMS intensites of gold-substrate signal $\left(A u^{+}\right)$and a prominent protein secondary ion $\left(\mathrm{C}_{5} \mathrm{H}_{10} N^{+}\right)$. b XPS surface quantification of the samples under study

along the PC\#1 axis and extend towards the cluster of the clean substrate samples: This is again an indication for the pronounced tendency of collagen to de-wet from the thiol surface exposing the bare substrate in some areas. On the other hand, no such spreading can be seen for the samples where a pre-adsorbed $\mathrm{H}^{*}$ Protein layer has been exposed to a solution of any secondary protein. This clearly indicates that the $\mathrm{H}^{*}$ Protein layer stays intact, without any significant detectable change in chemical composition and we thus conclude that protein exchange does not occur within days, contrary to surface modifications reported with other proteins [4]. The affinity of $\mathrm{H}^{*}$ Protein for binding on the hydrophobic substrate thus again proves remarkably high compared with other proteins. With respect to the Vroman effect [32], which in general describes a higher affinity of proteins towards surfaces with increasing molecular mass, $\mathrm{H}^{*}$ protein shows the highest affinity in our study, even though $\mathrm{H}^{*}$ Protein itself has the lowest molecular mass among the proteins used. Certainly, its strong tendency for structure formation at interfaces must play a role [12].

\section{Conclusions}

By a combination of several surface analytical techniques, we could show that an adsorbed layer of $\mathrm{H}^{*}$ Protein $\mathrm{B}$ completely prevents secondary adsorption of BSA, casein, and collagen at low-salinity conditions and at $\mathrm{pH}$ 8. These findings are based on conclusive, coherent data from QCM-D, ellipsometry, XPS, and ToF-SIMS. The anti-adhesive property of $\mathrm{H}^{*}$ Protein $\mathrm{B}$ is another manifestation of the "twofold", Janus-like nature of these remarkable proteins: depending on the choice of conditions, hydrophobin can be used both for effective prevention as well as for facilitating adhesion of proteins. Beyond the analysis of total adsorbed protein by quartz-crystal microbalance and ellipsometry, we have proven by XPS and ToF-SIMS for the first time that the $\mathrm{H}^{*}$ Protein B layer stays completely intact even after more than $10 \mathrm{~h}$ of exposure to solutions of the secondary proteins, without any detectable exchange. Further studies are needed to explore whether and to what degree these properties can be exploited under other, e.g., physiological conditions at higher salinity and/or varied $\mathrm{pH}$. The combination of methods presented in this contribution should provide a helpful basis for such investigations.
Fig. 7 Result of ToF-SIMS PCA by plotting the first two principal components $\mathrm{PC} \# 1$ and $\mathrm{PC} \# 2$ against each other. Clearly, a clustering of the different samples is seen. Ellipses are only drawn as guides to the eye. All proteins adsorbed on top of $\mathrm{H}^{*}$ Protein cluster together with pure $\mathrm{H} *$ Protein, proving the same protein layer composition and thus that no exchange is taking place

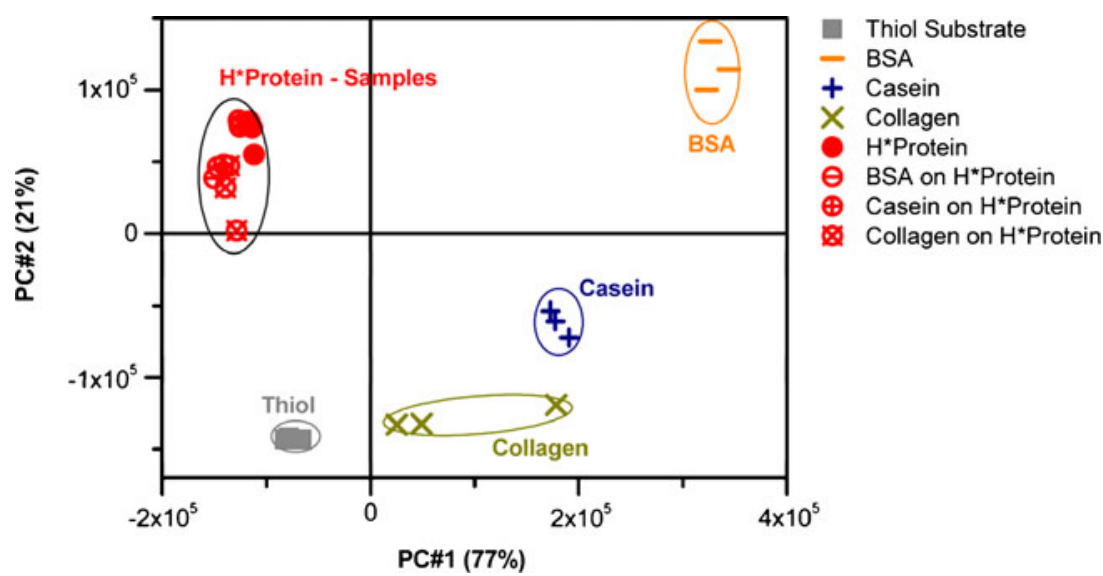


Acknowledgements The authors thank Mr. G. Lupa, Mr. H. Kullmann, Mr. W. Wacker, and Mr. S. Müller for excellent laboratory support and Dr. W. Schrepp for helpful discussions. Rui Xu acknowledges a RISE scholarship of the DAAD (German Academic Exchange Service).

Open Access This article is distributed under the terms of the Creative Commons Attribution Noncommercial License which permits any noncommercial use, distribution, and reproduction in any medium, provided the original author(s) and source are credited.

\section{References}

1. Bernsmann F, Lawrence N, Hannig M, Ziegler C, Gnaser H (2008) Anal Bioanal Chem 391:545-554

2. Reid G (2000) In: An YH and Friedman RJ (eds) Handbook of bacterial adhesion: principles, methods and applications. Humana Press Inc., Totowa

3. Jacobsen SM, Stickler DJ, Mobley HLT, Shirtliff ME (2008) Clin Microbiol Rev 21:26-59

4. Geelhood SJ, Horbett TA, Ward WK, Wood MD, Quinn MJ (2007) J Biomed Mat Res B 81B:251-260

5. Ratner BD (2004) Biomaterials science: an introduction to materials in medicine. Elsevier, Amsterdam

6. Bell-Pedersen D, Dunlap JC, Loros JJ (1992) Genes Dev 6:2382-2394

7. Wessels JGH (2000) Mycologist 14:153-159

8. Wosten HAB, Van Wetter MA, Lugones LG, Van der Mei HC, Busscher HJ, Wessels JGH (1999) Curr Biol 9:85-88

9. Linder MB (2009) Curr Opin Colloid Interface Sci 14:356-363

10. Lumsdon SO, Green J, Stieglitz B (2005) Colloids Surf B 44:172178

11. Hou S, Li X, Li X, Feng X-Zxec, Wang R, Wang Cwc, Yu L, Qiao MQ (2009) Anal Bioanal Chem 394:783-789

12. Wohlleben W, Subkowski T, Bollschweiler C, von Vacano B, Liu YQ, Schrepp W, Baus U (2010) Eur Biophys J Biophys Lett 39:457-468

13. Santhiya D, Burghard Z, Greiner C, Jeurgens LPH, Subkowski T, Bill J (2010) Langmuir 26:6494-6502

14. Wessels JGH (1994) Annu Rev Phytopathol 32:413-457
15. Takahashi T, Maeda H, Yoneda S, Ohtaki S, Yamagata Y, Hasegawa F, Gomi K, Nakajima T, Abe K (2005) Mol Microbiol 57:1780-1796

16. Corvis Y, Walcarius A, Rink R, Mrabet NT, Rogalska E (2005) Anal Chem 77:1622-1630

17. Wang ZF, Lienemann M, Qiau M, Linder MB (2010) Langmuir 26:8491-8496

18. Sauerbrey G (1959) Z Phys 155:206-222

19. Suzuki N, Gamble L, Tamerler C, Sarikaya M, Castner DG, Ohuchi FS (2007) Surf Interface Anal 39:419-426

20. Lee JLS, Gilmore IS (2009) In: Gilmore IS, Vickerman JC (eds) Surface analysis - the principal techniques. New York, Wiley

21. Fairley N (2010) CasaXPS VAMAS processing software. Available at: http://www.casaxps.com

22. Shirley DA (1972) Phys Rev B 5:4709-4714

23. Moulder JF, Stickle WF, Sobol PE, Bomben KD (1992) Handbook of X-ray photoelectron spectroscopy. Perkin-Elmer, Eden Prairie, Physical Electronics Division

24. Rodahl M, Kasemo B (1996) Sens Actuators, A 54:448-456

25. Hook F, Kasemo B, Nylander T, Fant C, Sott K, Elwing H (2001) Anal Chem 73:5796-5804

26. Voinova MV, Rodahl M, Jonson M, Kasemo B (1999) Phys Scr 59:391-396

27. Hook F, Voros J, Rodahl M, Kurrat R, Boni P, Ramsden JJ, Textor M, Spencer ND, Tengvall P, Gold J, Kasemo B (2002) Colloids Surf B 24:155-170

28. Xu SH, Yamanaka J, Miyata I, Yonese M (2007) Colloid Polym Sci 285:899-906

29. Dupont-Gillain CC, Jacquemart I, Rouxhet PG (2005) Colloids Surf B 43:179-186

30. Hirayama K, Akashi S, Furuya M, Fukuhara K (1990) Biochem Biophys Res Commun 173:639-646

31. Michaelis L, Pechstein H (1912) Biochem Z 47:260-268

32. Vroman L (1962) Nature 196:476-477

33. Berman ESF, Wu LG, Fortson SL, Kulp KS, Nelson DO, Wu KJ (2009) Surf Interface Anal 41:97-104

34. Michel R, Castner DG (2006) Surf Interface Anal 38:1386-1392

35. Park JW, Min H, Kim YP, Shon HK, Kim J, Moon DW, Lee TG (2009) Surf Interface Anal 41:694-703 